\title{
Diagnostic studies for common invasive and infectious pathologies of rabbits in the Orenburg region
}

\author{
Z.Kh. Terentyeva ${ }^{1, *}$, R.Sh. Taiguzin ${ }^{1}$, O.A. Matveev ${ }^{1}, K h . K h$. Shakhbiyev $^{2}$, and \\ A.L. Kryazhev ${ }^{3}$ \\ ${ }^{1}$ Orenburg FSBEI HE Orenburg SAU, Orenburg, Russia \\ ${ }^{2}$ Chechen State University, Grozny, Russia \\ ${ }^{3}$ Federal State Budgetary Educational Institution of Higher Education Vologda State Dairy \\ Academy named after N.V. Vereshchagin, Vologda, Russia.
}

\begin{abstract}
Rabbits, like other animal species, are susceptible to infection with invasive and infectious diseases. Both ecto- and endoparasites are registered in them, including helminths, insects on the body, acarus scabies, protozoa. Rabbits are characterized by a high degree of precocity, high fecundity and the breadth of use of the products obtained from them. As a product of rabbit breeding, first, meat is in demand as a dietary product. Part of the products from rabbits - hair, wool-molt is obtained during the life of the animal, and meat, skins, other products - after slaughter. Skins and rabbit hair are used for the manufacture of fur products, as well as in the felt and knitting industry. In addition, biologists, doctors, veterinarians use rabbits as laboratory animals in scientific research, for testing cosmetics, as well as in laboratories and bio factories for drug testing. To preserve the population of these species, it is important to prevent infection with various pathologies inherent in rabbits, including invasive diseases.
\end{abstract}

\section{Introduction}

Rabbits, in comparison with farm animals, are distinguished by their precocity, high fecundity, and the breadth of use of the products obtained from them. The products of rabbit breeding as a food product primarily include meat, which is in demand as a dietary product. Such products from rabbits as - hair, wool-molt are obtained during the life of the animal, and meat, skins, and other products - after slaughter. Skins and rabbit hair are used for the manufacture of fur products, as well as for the manufacture of felt and knitwear. In addition, biologists, doctors, and veterinarians use rabbits as laboratory animals, as well as in scientific research, for testing cosmetics, and in laboratories and bio factories for drug testing $[1,2]$.

\footnotetext{
*Corresponding author: zoy19570501@mail.ru
} 
The quality and quantity of rabbit breeding products depends on the breed and hereditary characteristics of animals, on the impact of various environmental factors, on the economic use of this type of animal and on the type of animal maintenance, as well as on various pathologies, including infestations inherent in this type of animal $[3,5,6,10,13$, 14]. In Russia, in 1927, the breeding of rabbits was mainly amateur in nature, during this period, several thousand high-value breeds were imported to the country such as: Belgian Hare, chinchilla (small), white giant, Viennese white, Viennese blue, champagne, Angora ram, Havanna. In 1929-1931, large rabbit farms were established in different parts of the country for breeding pedigree animals. At that time, the main task of the rabbit breeding revival was the reproduction of breeding rabbits by crossing with purebred animals and thereby improving the quality of local mongrel animals $[4,7,9,14]$.

During this period, factories for processing of rabbit skins were built in the country. Thus in 1934-1935, the volume of rabbit skin products in the fur processing industry was $35 \%$. The range of products from rabbit raw materials was diverse and high-quality skins were produced, both in natural form and imitated for more valuable furs (beaver, leopard, cat, sable), which were used to make hats, women's coats, collars, jackets. From skins unsuitable for the fur industry, leather was made for the manufacture of haberdashery products, light shoes. Felt boots, hats, berets, and other items were made from rabbit hair, and high-quality berets, sweaters, children's suits, shawls, scarves, stoles, gloves, $[8,9]$ were made from the hair of Angora rabbits.

Currently, several rabbit farms are engaged in rabbit breeding in Russia, including: LLC "Agricultural enterprise "Kroliks", in the Leningrad region, Rabbit breeding farm "Ushastiy Dvorik" in Novoorsk (Orenburg region), CJSC APCC "Roshchinsky", in Tyumen, the Company "Agrocomplex" in the vil. Vyselki (Krasnodar Krai), LLC "Agricultural Enterprise "Kroliks", Volosovo, city of Argun, the Chechen Republic, and some others.

The purpose of our research was to identify the most common invasive and infectious pathologies of rabbits and to clarify the dynamics of prevalence in farm and individual households of owners in the territory of Orenburg region.

The tasks of diagnostic studies were to determine the prevalence of invasive pathologies in rabbits on the basis of helminthologic, pathoanatomic studies and veterinary and sanitary assessment of slaughter products.

\section{Materials and Methods}

The material on the study of the species composition of pathogens of rabbit infestations in individual and rabbit farms was collected by us for several years. As a result of the conducted studies (helminth coprological studies, post-mortem examination, veterinary and sanitary assessment of slaughter products) in such farms as: individual farm Evdokimova M.I. (Ivanovka), Govorova K.N. (Kushkuli), Egorova Yu.A. (vil. Vostochny), Petrova Yu.P. (vil. Rostoshi), Kalantaryan G.G. (Nezhinka), subsidiary farm at the fire station (vil. Chebenki) and others, we studied rabbits of different age groups, in different seasons of the year, with different types of housing.

\section{Results and Discussion}

During helminth coprological studies, autopsy of rabbit corpses, veterinary and sanitary assessment of slaughter products and carcass research, we registered such invasive diseases as: eimeriosis (coccidiosis of the liver and intestinal forms), cysticercosis pisiformis, passalurosis, dicroceliosis, fasciolosis, psoroptosis. Studying the material from rabbits in 
different individual and subsidiary farms, significant differences in the composition of the parasite fauna were noted. The dominant position in the prevalence of parasite species was occupied by pathogens belonging to the genus Eimeria. We have identified the following species:

1. E. intestinalis (Cheissin, 1948)

2. E. perforans (Leuckart, 1879)

3. E. magna (Perard, 1925)

4. E. stiedae (Lindemann, 1865)

5. E. media (Kessel, 1929)

During helminthologic studies in individual farms of the owners, monoinvasions were most often recorded in rabbits. In eimeriosis, the most common type of eimeria was $E$. perforans. This type of parasite in different degrees of intensity has been recorded and established in different age groups of rabbits. In descending order of the protozoa prevalence, the following were found, respectively: E. magna, E. intestinalis, and E. media. Other Eimeria species were very rare. In rabbits up to 2 months of age, Eimeria of $E$. perforans species dominated, with EI-22.0-24.0\%, and in 3-month-old rabbits - E. perforans and E. Intestinalis, respectively, 10.0-13.0\%. Similar types of pathogens were also found in rabbits up to 6 months of age (EI-6.7\%). In adult rabbits, all the listed types of protozoa pathogens were found, but with lower rates of invasion (EI-1.2-1.7\%), and in males, the degree of invasion and species composition was low, even in comparison with females $(0.2-4.0 \%)$. In the subsidiary farms of individual owners, 5 types of pathogens of eimeriosis were also identified: E. stiedae, E. intestinalis, E. magna, E. perforans, and E. media. Of these, Eimeria stiedae was the most widely distributed species.

The most unfavorable among all age groups of animals in terms of the degree of infection with eimeriosis were rabbits of 1-3 months of age. In animals of this age group, the intensity of invasion, depending on the farm in which they were raised, was in the range of $10.0 \pm 6.0-60.6 \pm 5.5$ ind. of eimerium oocyst in the field of vision of the microscope A high degree of eimeria oocysts (25.0 $\pm 7.0-50 \pm 9.0$ ind.) was observed in rabbits up to one month of age. The first isolation of eimeria oocysts in young animals of this group was observed at the age of 21 days. With an increase in the age of rabbits, including at 6 months of age, the intensity of eimeriotic invasion was low. At the same time, the intensity of the invasion was single oocysts.

In subsidiary farms, when analyzing the age dynamics of eimeriotic invasion among doe-rabbits and male rabbits, it was also found that females were most intensely invaded in comparison with adult male rabbits, which also had a low degree of invasion. The degree of infection of animals with eimeria in different farms differed significantly (EI - 2.0-26.0\%). The study of the seasonal dynamics of rabbit eimeriosis was carried out on the example of several farms with different animal housing: cage and floor in a heated capital premises.

The results of studies with cellular content showed that the peak of invasion occurred in the autumn-winter period, and the most invaded at this time were rabbits from 1 to 3 months. A low degree of invasion was observed in rabbits up to 1 month (5.0 $\pm 2.0-7.0 \pm 3.1$ ind.) and rabbits of 5-6 months of age and adult livestock. In the autumn period, eimeriotic invasion was recorded in the range of $60.6 \pm 5.5$ ind. of oocyst eimerium. In the autumnwinter period, an increase in the invasion intensity was observed in rabbits of all age groups. The high degree of invasion in the autumn-winter period is due to the increased humidity in the premises, which favorably affected the sporulation and development of oocysts. In the spring period, when the heat comes, the eimeriotic invasion was reduced due to the ventilation of the premises. In this season, the least infestation was observed in rabbits up to 30 days of age ( $10.2 \pm 1.6$ ind.) and in animals $1-2$ months (15.0+4.0 ind.). 
The study of the seasonal dynamics of eimeriosis with floor housing in capital-built premises showed that the indicators of prevalence dynamics in all periods of the year changed slightly and were approximately at the same level in each age group. Thus, in rabbits at the age of 30 days, according to the seasons of the year, the EI was $5.2 \pm 2.0 \%$ - in winter, and $3.0 \pm 2.75 \%$ - in summer. In rabbits of 3 months of age - from $20.3 \pm 2.0 \%$ to $25.2 \pm 1.8 \%$, similar changes in indicators were observed in animals of older age groups. In contrast to rabbits kept in cages, with the dynamics of infestations of animals located in heated rooms, the peak of infestation was observed from autumn to spring in rabbits at the age of up to 1-2 months.

During the veterinary and sanitary assessment of slaughter products with rabbit eimeriosis (coccidiosis), the affected organs (liver, intestines) are destroyed or disposed of, the depleted carcass is rejected, the carcasses of the first and second categories are used without restrictions.

When dissecting rabbits that died from eimeriosis, the body was depleted, and destructive changes were noted in the liver (Fig. 1). The liver is enlarged, dark in color on the surface of the organ and in the parenchyma of which there are also rounded whitishyellow overlays filled with the contents.

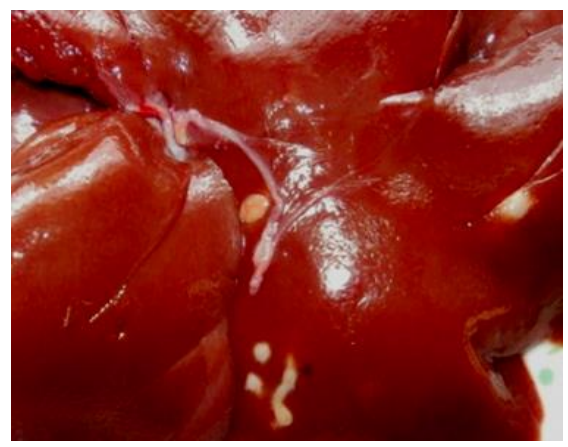

Fig. 1. Liver damage by Eimeria.

In the digestive tract: the intestinal mucosa is pale and yellowish, microscopic examination revealed the presence of clusters of oocysts (Fig. 2). On the mucosa, puffiness and redness were detected, as well as detachment of the epithelial layer of the intestine, covered with curd-like overlays with an admixture of blood and the presence of yellowish-white foci.

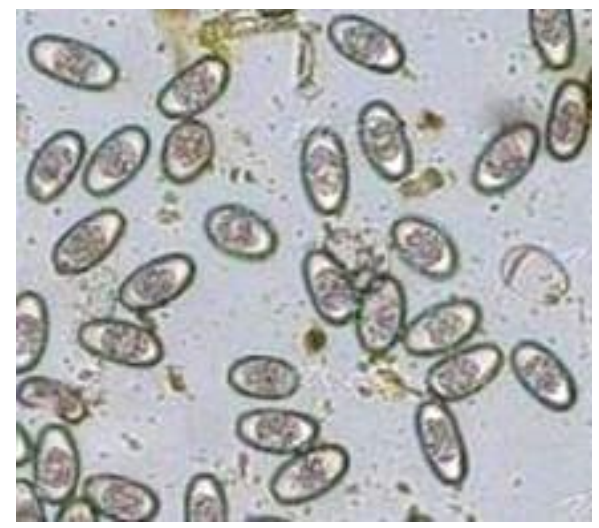

Fig. 2. Eimeria oocysts (high degree of invasion). 
The trematode - Fasciola hepatica causes fasciolosis in rabbits. When eating grass or hay from meadows and pastures affected by fasciolosis, rabbits become infected with fasciolosis. In the region of the Southern Urals, fasciolosis pathogens were found only in rabbits imported from the Stavropol Krai. During the coprological examination, single eggs of fascioles were identified in the field of visions of the microscope (Fig. 3)

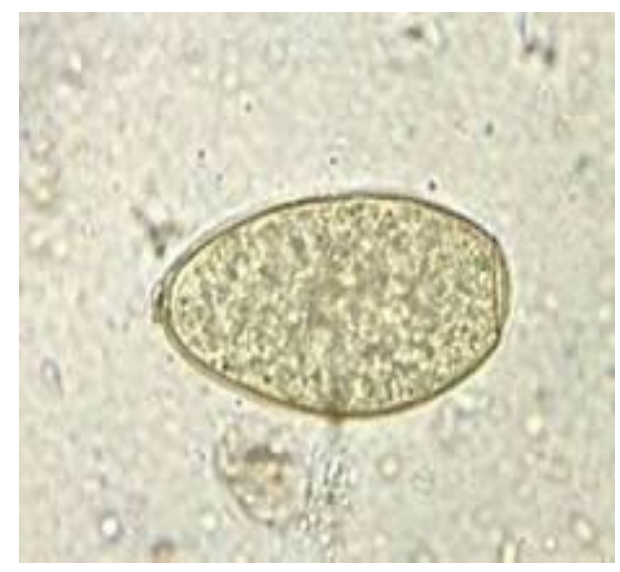

Fig. 3. Fasciola egg.

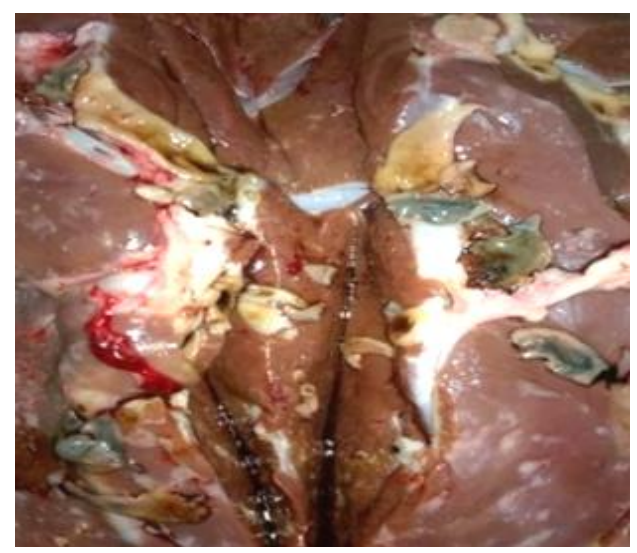

Fig. 4. Liver affected by fascioles.

If the liver is affected by fascioles, it is disposed of (Fig. 4), and the carcass is used without restriction, if there are no degenerative changes in the organs and tissues. If after the rabbit slaughter yellowish color remained in the carcass for 48 hours, it is also disposed of. When autopsies are performed on corpses, the conjunctiva is pale, the hair is matted, the mucous membranes are inflamed, and yellowish. The anus area is stained with fecal masses with bloody clots, there are signs of tympanitis. With a chronic course, the hair is brittle, easily falls out. There are edemas in the submandibular space, chest. The liver is slightly enlarged on autopsy.

In case of passalurosis of rabbits path. Passalurus ambiguus (Fig. 5) is localized in the large intestine 


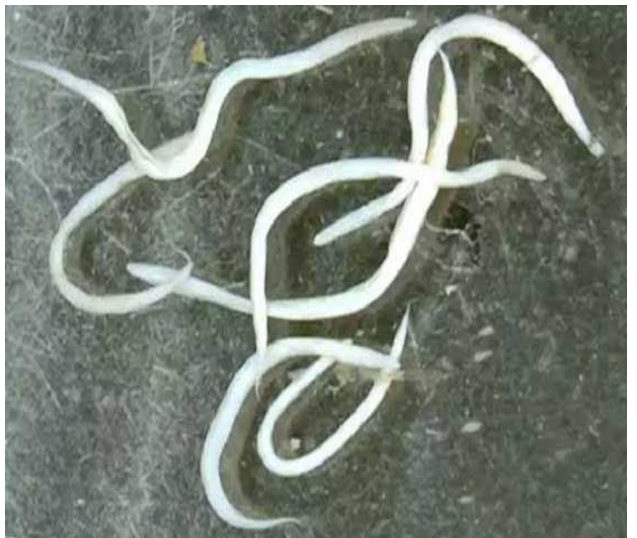

Fig.5. Passalurus ambiguus.

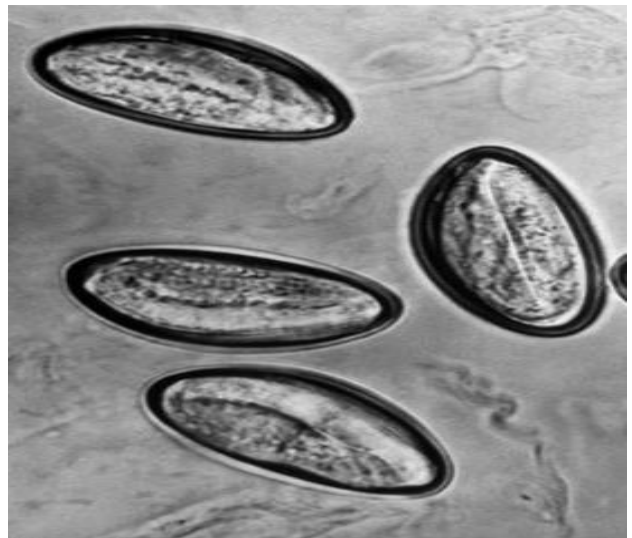

Fig. 6. Eggs of Passalurus ambiguus.

Passalurosis was registered mainly in animals with floor housing. During the helminthologic examination in the field of vision of the microscope, an average degree of invasion was noted (II-25-35 ind., EI-2.0-4.0\%) (Fig.6). The carcasses are atrophied, the mesenteric lymph nodes are enlarged, hyperemic, and swollen. In case of degenerative changes, the carcass is disposed of. On autopsy, serous-catarrhal and catarrhal-necrotic inflammation of the intestine was noted in rabbits. The mucosa of the caecum, rectum, and anus were hyperemic, edematous, with punctate hemorrhages. On autopsy of the large intestine, dozens of helminth specimens were found. There are traumatic injuries around the vulva and anus, due to scratching

In cysticercosis pisiformis (larval stage - Cysticercus pisiformis). An accurate diagnosis is established on the autopsy of corpses or at the veterinary and sanitary examination of rabbit carcasses after slaughter. Cysticercus were found on the serous membranes of the internal organs in the form of grapes (Fig. 7).
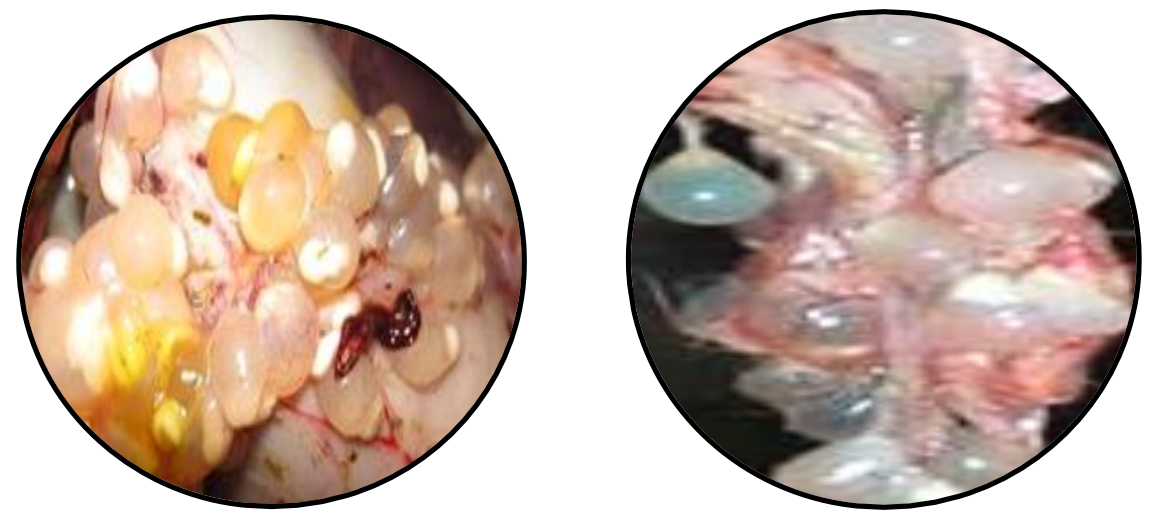

Fig. 7. Cysticercus on the serous membranes of internal organs.

At the same time, the liver was enlarged, dark cherry-colored, with hemorrhages in the parenchyma and hyperplasia of the bile ducts, serous-fibrinous peritonitis was noted. Carcasses and organs of rabbits with severe exhaustion and lesion of the mesenterium, omentum with thin-necked cysticercus are disposed of. In cysticercosis taenuicollis, the affected organs are rejected, the carcasses are used without restriction (Fig. 7).

The psoroptosis pathogens in rabbits is the mite Psoroptos cuniculi (Fig. 8), mainly adult rabbits are susceptible to this disease. The maximum degree of damage to rabbits is 
noted in the winter and early spring, due to a decrease in the body resistance. Inflammation of the external auditory canal and the inner surface of the auricle, which are covered with thick crusts, are developed in animals (Fig. 9). The pathology is accompanied by itching, the affected areas are infected with microflora, followed by the development of a purulent process and the accumulation of purulent-bloody mass, with a fetid smell. Sick rabbits lose their orientation. Rabbits are exhausted, they have seizures. Psoroptosis was recorded in rabbits aged over 7-8 months.
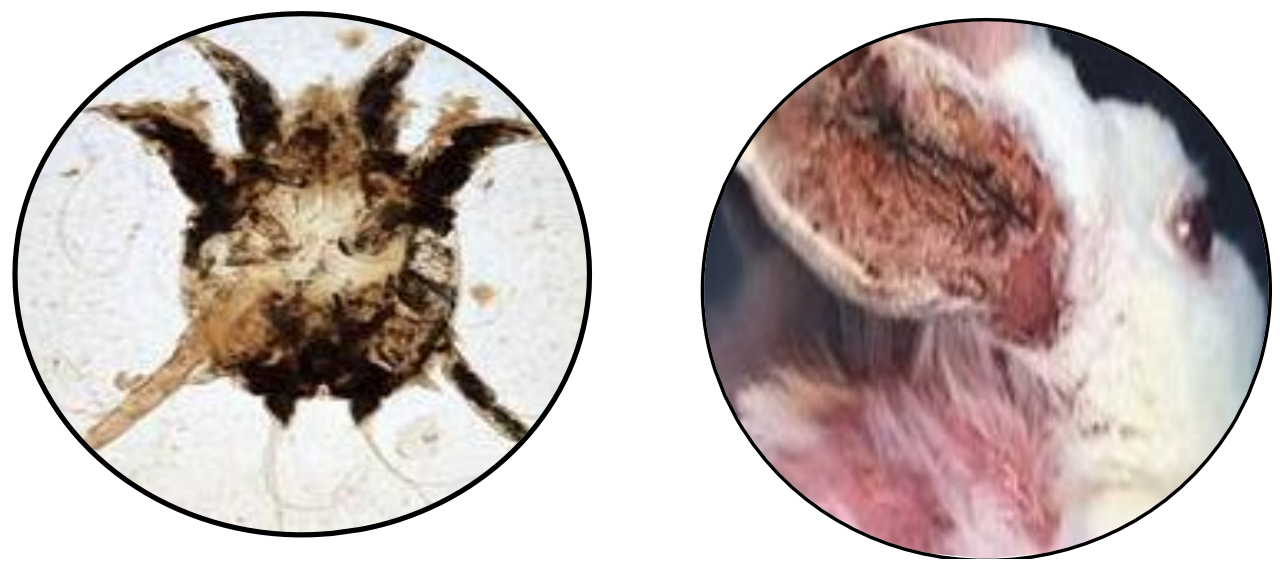

Fig. 8. Psoroptosis in a rabbit Figure 9 - Psoroptes cuniculi.

Infectious rhinitis was recorded from infectious pathologies of rabbits. Infectious rhinitis is caused by conditionally pathogenic microflora (Pasteurella, staphylococci, Pseudomonas aeruginosa, etc.) and all age groups of animals are susceptible to it. Animals have a reduced appetite, they sneeze, mucosal or purulent leak from the nose, light green discharge, crusts form in the nasal passages, there is difficulty and increased breathing. An increase in nose and swelling of the mucous membrane, while heavy breathing is noted. With this disease, rabbits die in 30-40 days. Of the 30 rabbits studied, 2 of them were infected with the infection (Fig. 10). Pathoanatomic changes. The nasal mucosa is hyperemic and edematous, covered with mucopurulent or purulent secretions. The mucous membrane of the trachea is swollen, hyperemic, with hemorrhages, the blood vessels of the trachea are blood-filled. The bronchial mucosa is also hyperemic, there is a foamy exudate in the lumen. Catarrhal, hemorrhagic, purulent-fibrinous or croup inflammation was noted with lung damage. There are hemorrhages on the surface of the lungs. The lower lobes of the lungs are swollen, and there are encapsulated abscesses in the tissues. 


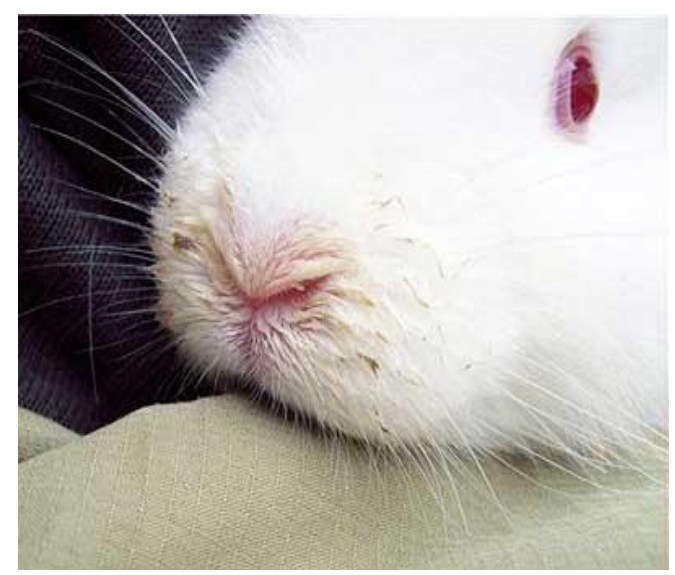

Fig. 10. Clinical manifestation of infectious rhinitis.

The diagnosis of infectious rhinitis was established on the basis of clinical and pathoanatomical studies, as well as using the results of a bacteriological study in the regional laboratory, where cultures of microorganisms from the lungs, heart, and blood were isolated with the establishment of pathogenic properties of pathogens on laboratory animals - white mice and rabbits. After confirmation of the viral etiology of the disease, a retrospective diagnosis was performed, examining the paired blood sera of rabbits in the reaction of delayed hemagglutination. At the same time, infectious rhinitis of rabbits was differentiated from rhinitis of non-infectious origin, which is characterized by the release of serous or serous-mucosal exudate from the nasal passages. In pasteurellosis, caseous lymphadenitis, aspergillosis, they are distinguished by the specific nature of the exudate for these pathologies and the results of laboratory tests.

Infectious keratoconjunctivitis is caused by different types of staphylococci. In this pathology, the cornea is affected, with turbidity and the appearance of ulcers, acquiring a white or yellowish-green color, conjunctivitis occurs with the release of purulent exudate, photophobia occurs, the epithelium is rough, with purulent or purulent-fibrinous exudate and ulcers, leading to an abscess, resulting in a thorn with vision loss. Animals lose weight and often followed by the death after 10-12 days from the onset of the disease. Of the 30 studied rabbits of different age groups, 5 of them were infected. Rabbits of different age groups were susceptible to the disease. The diagnosis was set on the basis of characteristic clinical signs and confirmed by bacteriological examination of the material in the laboratory from sick rabbits (Fig. 11). Pathoanatomical changes are similar to the data of the clinical picture of the disease. 


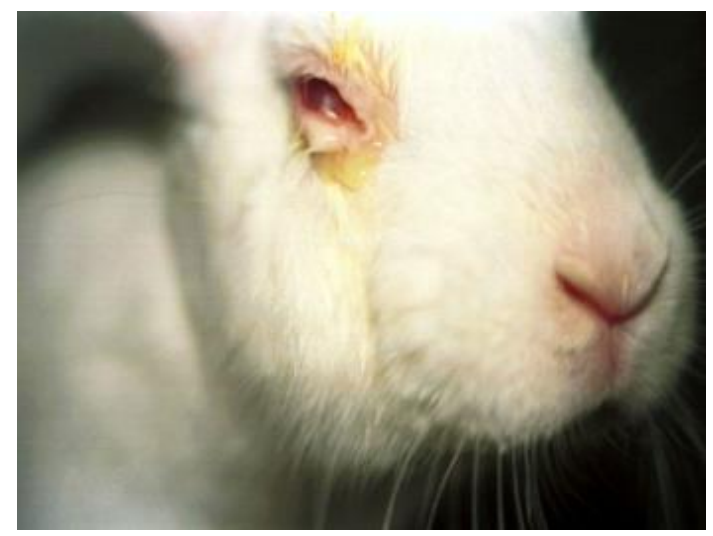

Fig. 11. Clinical manifestation of infectious keratoconjunctivitis.

\section{Conclusions}

Thus, when conducting diagnostic helminthological studies, during autopsy of corpses and veterinary and sanitary assessment of rabbit slaughter products and the study of carcasses, we obtained the following results:

1. In rabbits in the farms of the Orenburg region, during autopsy and coprological studies, such invasive diseases as eimeriosis (coccidiosis of the liver and intestinal forms), passalurosis were registered, in which the average indicators of II and EI were, respectively, from several units in fascioliasis, to several thousand individuals in eimeriosis;

2. During the veterinary and sanitary assessment of carcasses in different age groups of animals, cysticercosis pisiformis was detected with a degree of invasion of 25-27 ind., fasciolosis with an intensity of invasion - 15-30 ind.;

3. Such pathologies as: passalurosis, dicroceliosis, fascioliasis was less common, mainly in animals acquired in other regions, with a low degree of invasion;

4. Psoroptosis affected animals at the age of 3-4 months, with EI, on average, - 3-6\%;

5. The dominant invasion was eimeriosis, caused by several types of eimeria, in most cases, the intestinal form was recorded in rabbits;

6. Infectious keratoconjunctivitis and infectious rhinitis were more common among infectious pathologies. The intensity of the prevalence of these infections was at a low level, in comparison with invasive pathologies.

\section{References}

1. E.S. Volkova, V.N. Baimatov, Methods of scientific research in veterinary medicine 183 (M., KolosS, 2010)

2. V.V. Gorokhov, J. Veterinary medicine, 8, 3-5 (2002)

3. A.A. Dubnitsky, Proc. of the cent. of sc.-res. labor. fur farming, 6, 335-342 (1950)

4. A.A. Dubnitsky, Passalurosis. Diseases of rabbits, 184-190 (M. Kolos, 1974)

5. E.I. Kabanova, Diagnosis, clinical and ophthalmic characteristics and treatment of postoperative dry keratoconjunctivitis in small domestic animals, Veterinary surgery, Moscow (2021) 
6. B.E. Ketema, Eimeriosis of rabbits in different housing systems and improvement of control and prevention measures, Parasitology, Moscow (2002)

7. S.V. Leontyuk, A.A. Dubnitsky, et al. Diseases of rabbits, 235 (M., Kolos, 1974)

8. I.S. Minina, A.I. Mayorov, All about rabbits, Album, 210 (M., Kolos, 1985)

9. A.I. Rakhmanov, Home animal farm. Housing and breeding of rabbits and fur-bearing animals in the small garden plots, 256 (M., Aquarium LTD., 2000)

10. Z.Kh. Terentyeva, Russian Parasitological Journal, 4, 342-346 (2011)

11. Z.Kh. Terentyeva, Proceedings of the Orenburg State Agrarian University, 3 (41), 257$260(2013)$

12. Z.Kh. Terentyeva, E.P. Pyatachkova, Theory and practice of combating parasitic diseases, 17, 467-469 (2016)

13. L.I. Ulyikhina, Handbook of the rabbit breeder from A to Z, 256 (M., Aquarium-Print, 2009)

14. A.V. Uspensky, Veterinary consultant, 17, 10 (2003)

15. Yu.N. Shilyaeva, Eimeriosis of rabbits in the Republic of Tatarstan: Epizootology, control measures, Parasitology, Moscow (2004)

16. D.A. Sharafutdinov, Complex treatment of rabbits with experimental conjunctival keratitis, 45-47 (Notes of the KSAVM n.a. Bauman. Kazan, 2013)

17. A.A. Shevchenko, Diseases of rabbits, 224 (M., Aquarium-Print, 2009)

18. Katleen Hermans, Ilse Moeremans. E. cuniculiand other diseases in a geriatric rabbit. DVM Case Report as part of the Master`s Dissertation Ghent University faculty of veterinary medicine Academic year 2015, 234-238 (2016) 